\title{
Editorial
}

CPD update. G. Morgan

Original papers

Violence in the community: study of community mental health teams.

N. Eastwood and R. Pugh

Against a high-risk strategy in the prevention of suicide.

N. Kapur and A. House

Care programming and service change in a psychiatric sector.

S. Feeney, S. Onyett and K. Lindsay

Writing letters to patients. $P$. Thomas

Use of psychotropic medication in an adolescent in-patient unit.

P. McLoughlin, D. West, J. Phillips and D. Holman

Optimising neuroleptic treatment for psychotic illness. G. Searle

Olanzapine in practice. D. Taylor, S. Drummond and J. Pendlebury

Attendance at child psychiatry clinics. S. M. El-Badri and P. McArdle

Anti-bullying policy in child and adolescent psychiatric units.

$S$. Sommers and $L$. Whitney

Attendees at a primary care-based mental health promotion drop-in clinic. C. Gilleard and R. Lobo

Nature and extent of dental pathology and complications arising in patients receiving ECT. N. Beli and P. Bentham

Co-occurrence of Gilbert's syndrome and psychosis.

A. S. Mahdi and M. S. Elameer

Butterflies, fractals and psychiatry. S. Reid

Trainees' Forum

Trainees' assessment and management of mental illness in adults with mild learning disabilities. K. Sayal and S. Bernard

\section{Psychiatry and literature}

The detective, the psychiatrist and post-modernism. A. Beveridge

\section{History of psychiatry}

Workhouse or asylum: the nineteenth century battle for the care of the pauper insane. E. D. Myers

\section{Briefing}

Dilemmas of a psychiatrist in a developing country. S. B. Malik

\section{Computers in psychiatry}

Self-diagnosis and attitude change through the 'information super highway'. $O$. Ayonrinde and S. Michaelson

\section{Psychiatric vignette}

Jung at heart. R. Clarke

\section{Correspondence}

The College

Distinction Awards: the system in England and Wales 